\title{
INTEGRATION BETWEEN SURFACE AND SUBSURFACE SPATIAL OBJECTS FOR DEVELOPING OMAN 3D SDI BASED ON THE CITYGML STANDARD
}

\author{
K. Al kalbani ${ }^{\text {a }}$, A. A. Rahman \\ 3D GIS Research Lab, Faculty of Built Environment and Surveying, Universiti Teknologi, Malaysia, 81310 UTM Skudai, Johor \\ Bahru, Malaysia-kulaib2020@gmail.com; alias@utm.my
}

KEY WORDS: 3D SDI, 3D City Model, CityGML, Surface and Subsurface 3D Spatial Objects

\begin{abstract}
The paper investigates the capability to integrate the surface and subsurface 3D spatial objects data structure within the 3D spatial data infrastructure (3D SDI) based on the CityGML standards. In fact, a number of countries around the world have started applying the 3D city models for their planning and infrastructure management. While others are still working toward 3D SDI by using CityGML standards. Moreover, most of these initiatives focus on the surface spatial objects with less interest to model subsurface spatial objects. However, dealing with 3D SDI requires both surface and subsurface spatial objects with clear consideration on the issues and challenges in terms of the data structure. On the other hand, the study has used geospatial tools and databases such as FME, PostgreSQL-PostGIS, and 3D City Database to generate the 3D model and to test the capability for integrating the surface and subsurface 3D spatial objects data structure within the 3D SDI. This paper concludes by describing a framework that aims to integrate surface and subsurface 3D geospatial objects data structure in Oman SDI. The authors believe that there are possible solutions based on CityGML standards for surface and subsurface 3D spatial objects. Moreover, solving the issues in data structure can establish a better vision and open new avenues for the 3D SDI.
\end{abstract}

\section{INTRODUCTION}

Nowadays, the infrastructures in the urban areas are complicated such as multi-floor buildings and underground utilities, which requires using 3D geo-datasets. Additionally, employing the $2 \mathrm{D}$ and $2.5 \mathrm{D}$ geospatial data may not be useful to analyze complex problems and so there is an urgent need to move to 3D geospatial data and 3D city model (Kitsakis et al., 2016; Roić, 2012; Stoter et al., 2015; van den Brink et al., 2013).

Currently, the 3D city model and their related applications are considering as good initiatives for representing the 3D spatial objects and entire cities. Moreover, the capability of current 3D geospatial technology has become capable to solve complex data structure issues. Hence, the need for 3D city model applications has increased within the government agencies and municipalities for various applications such as 3D cadastral and smart cities (Preka and Doulamis, 2016).

A number of countries around the world have applied the 3D city models for planning and infrastructure management, while other countries are working toward 3D SDI by using CityGML standard.

Moreover, most of these initiatives focus on surface spatial objects data structure with less interest to model subsurface spatial objects. However, dealing with 3D SDI requires a framework for integrating the data structure for both the surface and subsurface spatial objects. Moreover, since the current CityGML (version 2) standard has its limitation and focuses only on the surfaces spatial objects, there is a need to study how to extend the standards of CityGML (version 2) to accommodate the underground objects.

This paper is arranged into seven sections. The second section discusses the current CityGML standard. Then, section three investigates the 3D SDI and current status of 3D geospatial data in Oman including the motivation for utilizing CityGML as the standard for 3D SDI and the need for subsurface spatial objects within the 3D SDI. The experiments and discussion take place in section four and five, respectively. The paper proposes a framework to accommodate the surfaces and subsurface spatial objects within the 3D SDI in section six. The initial findings of the study are demonstrated in final seven.

\section{CityGML STANDARD}

CityGML initiatives have been developed by the Special Interest Group3D (3D SIG) and it is organized now by Open Geospatial Consortium (OGC). In addition, CityGML has been recognized to be the international standard for exchanging the format of 3D geospatial objects and the 3D city model based on the XML file format and the GML 3xx. In addition, CityGML (version 2) includes 13 models to store spatial objects and 5 levels of detail (LoD) (Biljecki, 2017; Biljecki et al., 2015b; Stouffs et al., 2018).

On the other hand, the standard of CityGML mainly focuses on the spatial perspective, unlike the Industry Foundation Classes (IFC) standards and Building Information Modeling (BIM) (Arroyo Ohori et al., 2018; Biljecki et al., 2016, 2015a; Kensek, 2014). Hence, CityGML presents the most common (natural and human) spatial features that can be found in the cities and their surrounding with determining their geometric and semantic information. In fact, the CityGML standard gives more focus to the building model- schema more than other schemas. Moreover, the concept of CityGML allows decomposing the spatial objects to sub-spatial objects like buildings (Figure 1) (Arroyo Ohori et al., 2018; Biljecki, 2017; Biljecki et al., 2017, 2015a, 2015b; Kensek, 2014; Stoter et al., 2016). 


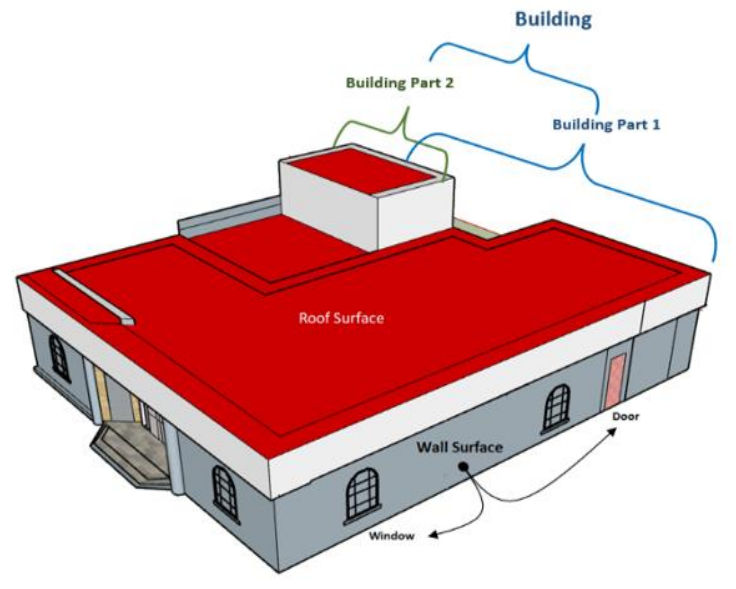

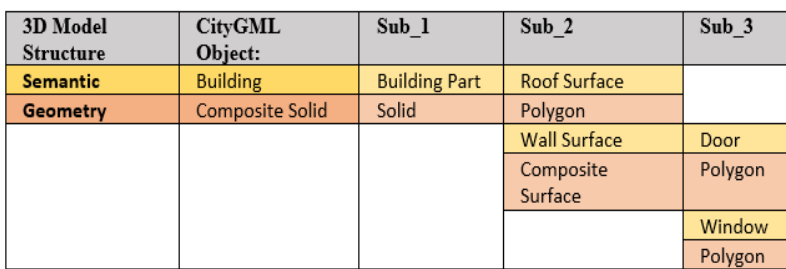

Figure 1. Decomposing the building to sub- spatial objects in CityGML

\section{3D SPATIAL DATA INFRASTRUCTURE (3D SDI)}

The 3D SDI is kind of a platform that includes all the geospatial activates starting from a vision to the data (Kalantari Oskouei et al., 2018; Rajabifard and Coleman, 2012). In addition, it has become one of the solutions for planning and managing many smart cities. Moreover, the 3D data is greatly required for urban, utilities, security, public safety and municipal entities (Li et al., 2013; Mao, 2014; Salim, 2017). Furthermore, 3D SDI has a wide range of benefits as it can reduce costs, save time, increase accuracy and improve efficiency. It can also improve workflows, increase productivity, manage resources, enhance the quality of services, support decision making and offer further functionality through the 3D dimension.

Most of 3D SDI projects around the world even in the developed countries face lots of challenges that affect the SDI implementation process and sometimes it stops at various stages. In fact, the most challenges and issues facing the implementation of 3D SDI is how to create 3D city model data structure from different 2D and 3D data models available in the geospatial society.

In addition, there are other obstacles can be encountered such as 3D geospatial data complexity format, 3D legation and policy, 3D objects registration, 3D geospatial data management, 3D modeling and presenting information (Alsultan and Rahman, 2015; Biljecki et al., 2015b; Breunig et al., 2015; Decontamination, 2016; Delgado Fernández et al., 2008; Ellul, 2016; Ho et al., 2015; Makanga and Smit, 2010; NCSI, 2017a; Rajabifard and Coleman, 2012; Salim, 2017; Stoter et al., 2015; Zhao et al., 2007).

Oman has made noticeable progress in integrating the 2D and 2.5D geospatial data into Oman SDI in most of its governance infrastructure (Figure 2) (NCSI, 2017a, 2017b). In contrast, up to now, there is no serious implementation for $3 \mathrm{D}$ geospatial data and 3D model both in the public and private sector in Oman. As reported by NCSI, (2017a, 2017b) most of the Omani government sectors keep the geospatial data flowing at the level of the 2D and 2.5D geospatial data. Nevertheless, the geospatial society in Oman needs 3D geospatial solutions to manage complex data structure for surface and subsurface spatial objects. What is also crucial is that Oman National Spatial Data Infrastructure (ONSDI) and other geospatial sectors have to revamp their visions, objectives and standards to meet the requirements for $3 \mathrm{D}$ city model and $3 \mathrm{D}$ SDI.

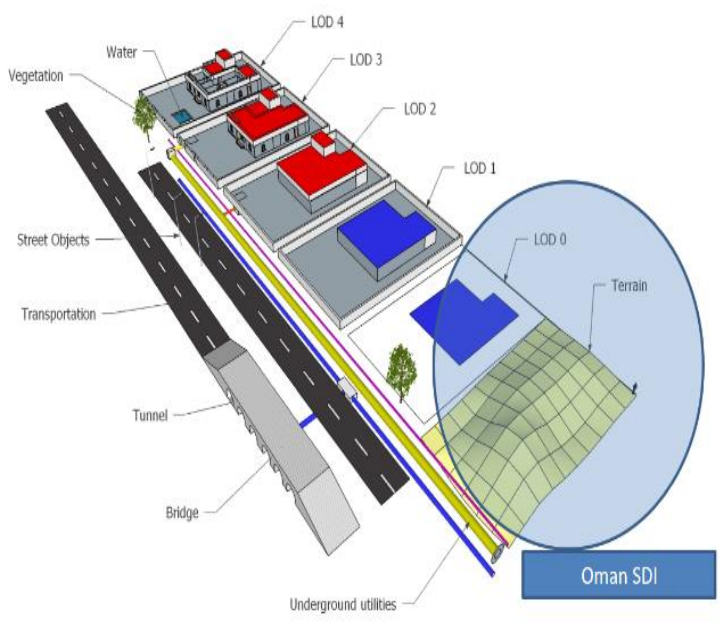

Figure 2. Oman SDI geospatial core business

\subsection{The Motivation for Utilizing CityGML as Standard for 3D SDI}

CityGML is open XML file format for exchanging, storing and representing 3D objects. In addition, the structure of CityGML file format is developed based on hierarchy structure both for geometric and semantic information. On the other hand, different geospatial vendors have integrated their GIS products with CityGML extension for reading, writing and viewing in CityGML format.

Moreover, CityGML has been supported with some solutions in terms of providing database structure which is suitable with CityGML standard such as PostgreSQL-PostGIS, Oracle, and 3D City Database (3D City DB). In fact, now there are various spatial applications for CityGML such as solar potential, flood risk, and noise monitoring. (Biljecki, 2017; Biljecki et al., 2015b; Preka and Doulamis, 2016; Soon et al., 2016; Yao et al., 2018).

\subsection{Need for Subsurface Spatial Objects within the 3D SDI}

The change of urban growth, as well as the speed of urban sprawl components, both has caused such limitations in the lands that are valid for construction. Hence, it has played an important role to drive the megacities around the world to start establishing their construction in subsurface such as train tunnel, shuttle, and pipeline. Furthermore, all objects in the surface and subsurface are built in space filled with soil and rock. Thus, it is essential to determine the potential risks and unexpected issues that may influence the construction. This may lead to raise a lot of questions regarding the importance to create 3D City model that accommodates both surface and subsurface spatial objects (Bisheng et al., 1999; Duncan and Rahman, 2013; Gemeda, 2012; Kolbe and Gröger, 2003; Liu et al., 2009; Rienzo et al., 2008; Salim, 2017; van den Brink et al., 2013; Wang et al., 2018; Yan et al., 2018) . 
Most of the current 3D city models represent different phenomena and objects above the surface with little interest to display subsurface spatial objects in 3D. On the other hand, there are some models which have been designed to manage undergrounds utility objects such as CityGML utility network ADE, IFC, ArcGIS utility model, and the INSPIRE utility networks model. In addition, these models support visualization, storage, analysis, and exchange. In fact, most of these solutions focus on 2D geospatial data without $3 \mathrm{D}$, with the exception of the CityGML utility network ADE and the IFC utility model (Arroyo Ohori et al., 2018; Yan et al., 2018).

The subsurface geological model is an important model for any 3D city model and underground services management. Moreover, it assesses the degree of risks and the possible impacts on the city infrastructure (surface and subsurface). In addition, it considers a useful tool to calculate the cost-benefit before real construction.

Several studies have discussed the geological model and city model from perspectives of geographic information system (GIS) and engineering (Gang Liu et al., 2009). On the other hand, there are rarely studies that link between the geological model and CityGML standard and most of these studies have adopted GML in their methodology.

In contrast, the extracting for the 3D geological data is not an easy task to be implemented in cities, where most of the cities already are covered by building and other infrastructures. Moreover, the extraction of such data entails different technologies such as semi survey and vertical samples for digging the wells. Photogrammetry and laser scanning can also be used to create a geological land cover map (LoD 0).

Another issue is that there are various 3D geological models which have been created by using different geological standards and approaches (Gang Liu et al., 2009). Thus, there are urgent needs to harmonize all the 3D geological models to create a unified 3D geological model. At this point, GeoSciML is considered as a basic standard based on XML to transform the geological models and objects and could be widely used in the oil and gas industry. Moreover, the GeoSciML has been adopted in the OGC standards.

Furthermore, the China Geological Survey has taken the 3D geological modeling and the GeoSciML to the next level through publishing the Geo3DML. Nowadays, Geo3DML is considered as a good initiative to unify and exchange geological models. Moreover, the Geo3DML has accommodated various geological models including drills, cross-sections/geo-maps, and 3D models. Additionally, the Geo3DML uses the same OGC standards and GML extensions (Wang et al., 2018).

\section{EXPERIMENTS}

In order to figure out the issues and challenges to develop 3D SDI based on CityGML standard including surface and subsurface spatial objects, the study has carried some experiments in a pilot area in Oman. The study has collected the data from the related geospatial agencies in Oman (2D, 2.5D geospatial data). Moreover, the study has used geospatial tools and databases such as FME, PostgreSQL-PostGIS, and 3D City Database. These aforementioned tools and databases were used to generate the $3 \mathrm{D}$ model and to test the capability for integrating the surface and subsurface 3D spatial objects data structure within the 3D spatial data infrastructure (3D SDI).
To convert the geospatial data structure obtained from the study area to the 3D model based on CityGML standard, the experiments have used the FME as an exchanging tool. Consequently, the buildings, pipeline networks, and geological strata in the study area were all generated in LoD1 and LoD2 CityGML files (Figure 3).

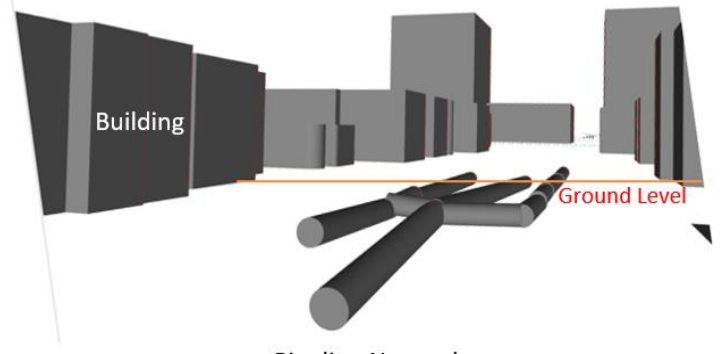

Pipeline Network

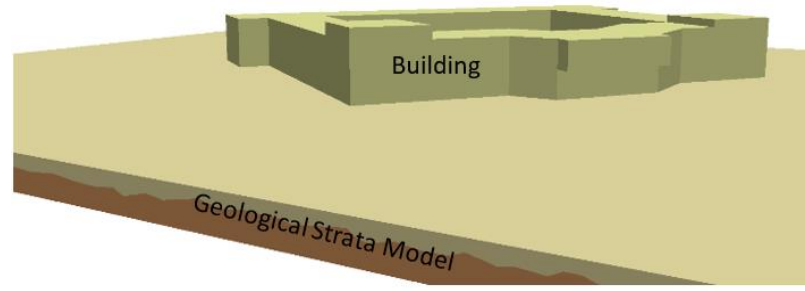

Figure 3. Creating a 3D model for some surfaces spatial object (building) and subsurface objects (pipeline networks and geological strata model)

Furthermore, the study has utilized PostgreSQL-PostGIS to create a geospatial database (oman_citydb_2019) based on the Omani Coordinate Reference System(CRS). In addition, the 3DCityDB was linked with the database to export the 3D geospatial data models and to check the capability for structuring and integrating both schemas of surfaces spatial object (building) and subsurface spatial objects (pipeline networks and geological strata).

The final database of this study has been created including CityGML and KML files. In addition, some of the results have exported from 3DCityDB using KML/COLLADA plugin (Figure 4).

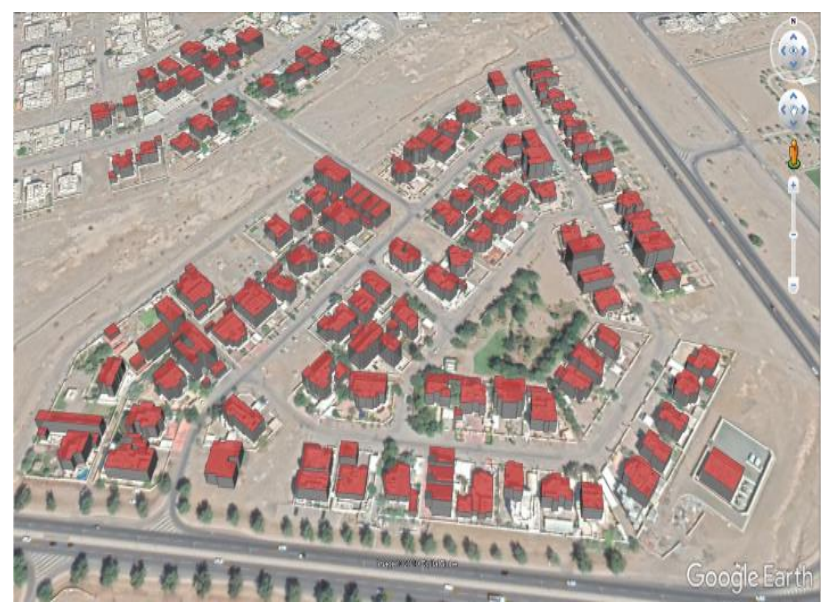

Figure 4. Part of 3DCityDB in KML file 


\section{DISCUSSION}

Through modeling and integrating the spatial objects for surface and subsurface within the pilot area, the study has found that the most issues are caused by modeling subsurface spatial objects like pipeline network and geological data. In fact, the CityGML does not provide a valid standard to support subsurface objects except for the CityGML utility network ADE for utility network (not published in CityGML standard yet). Since there is no clear standard for subsurface objects on CityGML standard (version 2), some experiments were carried out in the study to develop its own 3D model inherited from CityGML standard for some subsurface spatial objects such as pipeline networks and geological strata models.

Additionally, the 3D generated model still needs to address some issues in its data structure. These issues are categorized in terms of the CRS/SRID, quality of data structures, poor geomatics representation, the problem of semantic cording, creating the data structure in terms of schema(s) and $\operatorname{LoD}(\mathrm{s})$, integration with the DTM, and the topology issues. Other issues are related to encoding information standardized rules and how to manage the interplay relationships between different subsurface spatial objects under the earth's surface. Thus, if the existence of these challenges in the data structure is not processed, it will affect later the database management and contribute to the reduction of its effectiveness.

In addition, it is very crucial for 3D SDI and 3D city model to answer the spatial queries of different clients. Thus, the study which is based on the experiments has found that the database structure for surface spatial objects can be created through the integration of PostgreSQL-PostGIS, and 3DCityDB (open source). Hence, SQL queries and other simple spatial analysis such as distance, length, and others can be executed by using SQL scripts in the database. Our tests also show that the 3DCityDB is suitable for the surface spatial objects (building, bridge, water), and other schemas defined in CityGML standard (version 2). On contrast, since there is no schema(s) until now for subsurface spatial objects in CityGML standard (version 2), the subsurface spatial objects (pipeline and geological spatial objects) are still not defined in the feature classes of the 3DCityDB.

Theoretically, subsurface models can be added to the databases under the specific of CityGML standard (version 2) classifications, but the problem is that the spatial data are not valid for the analysis due to the problems mentioned earlier.

\section{DEVELOPING FRAMEWORK FOR SURFACES AND SUBSURFACE SPATIAL OBJECTS WITHIN THE 3D SDI}

Developing a framework and data structure for surfaces and subsurface spatial objects within the 3D SDI is a complex task. Therefore, the study proposes a framework (Figure 5) for developing the $3 \mathrm{D}$ city model within the upcoming Oman 3D SDI.

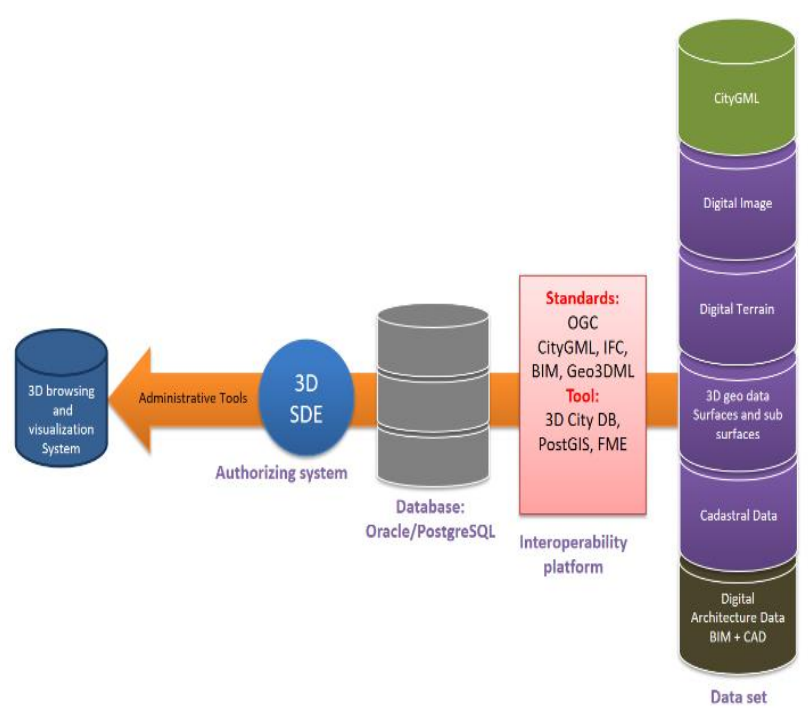

Figure 5. Developing framework for surfaces and subsurface spatial objects within the 3D SDI

In addition, the framework includes different resources for 3D geospatial data (surface and subsurface spatial objects), interoperability platform uses different standards, database accommodates the structure of surface and subsurface, 3D SDE, administrative tools, and the $3 \mathrm{D}$ visualization system. The framework points out that the 3D city model within the 3D SDI needs efficient management for the 3D spatial database (DBMS) to meet the 3D application requirement in different agencies. Moreover, the 3D database engine (SDE) is a necessary element to manage the access and relationship between the database and 3D model functionality such as 3D query, $3 \mathrm{D}$ analysis, and $3 \mathrm{D}$ visualization.

\section{CONCLUSION AND OUTLOOK}

This paper attempts to investigate the capability to integrate the surface and subsurface 3D spatial objects data structure within the 3D spatial data infrastructure (3D SDI) based on the CityGML standard.

The final remark of the study shows that there is a capability to create subsurface spatial objects based on CityGML standard but they are still some issues that need to be tackled in terms of geometric, semantic information and other challenges. Moreover, the standard of CityGML is still in progress and is not stable enough to meet the requirements of 3D SDI.

In addition, the current CityGML standard (vision 2) and 3DCityDB do not support the subsurface spatial object effectively. Hence, there is an urgent need for 3D SDI if the CityGML is chosen as the standard to fill this gap and develop a unified standard for the subsurface object within the CityGML standard. On the other hand, efforts to make the 3D SDI successful initiatives which require a homogenous and stable environment of all the standards (CityGML, IFC, BIM, and others) that used to exchange the three-dimensional spatial data. In the future, based on the initial results, we would like to investigate this matter further by exploring possible solutions to integrate the 3D subsurface spatial objects within the 3D SDI. 


\section{REFERENCES}

Alsultan, S.H., Rahman, A.A., 2015. Kingdom of Saudi Arabia Geospatial Information Infrastructure; An Initial Study. ISPRS - Int. Arch. Photogramm. Remote Sens. Spat. Inf. Sci. XL2/W4, 95-99. https://doi.org/10.5194/isprsarchives-XL-2-W495-2015

Arroyo Ohori, K., Biljecki, F., Kumar, K., Ledoux, H., Stoter, J., 2018. Modeling Cities and Landscapes in 3D with CityGML, in: Building Information Modeling. Springer International Publishing, Cham, pp. 199-215. https://doi.org/10.1007/978-3319-92862-3_11

Biljecki, F., 2017. Level of Details in 3D City Models,Published PhD Thesis. Delft University of Technology. https://doi.org/10.4233/uuid:f12931b7-5113-47ef-bfd4688aae3be248

Biljecki, F., Ledoux, H., Du, X., Stoter, J., Soon, K.H., Khoo, V.H.S., 2016. The Most Common Geometric And Semantic Errors In Citygml Datasets. ISPRS Ann. Photogramm. Remote Sens. Spat. Inf. Sci. IV-2/W1, 13-22. https://doi.org/10.5194/isprs-annals-IV-2-W1-13-2016

Biljecki, F., Ledoux, H., Stoter, J., 2017. Generating 3D City Models Without Elevation Data. Comput. Environ. Urban Syst. 64, 1-18. https://doi.org/10.1016/j.compenvurbsys.2017.01.001 Biljecki, F., Ledoux, H., Stoter, J., 2015a. Improving the Consistency of Multi-LOD CityGML Datasets by Removing Redundancy. pp. 1-17. https://doi.org/10.1007/978-3-31912181-9_1

Biljecki, F., Stoter, J., Ledoux, H., Zlatanova, S., Çöltekin, A., 2015b. Applications of 3D City Models: State of the Art Review. ISPRS Int. J. Geo-Information 4, 2842-2889. https://doi.org/10.3390/ijgi4042842

Bisheng, Y., Qingquan, L.I., Deren, L.I., 1999. Building Modeling for 3d City Model. Geo-Spatial Inf. Sci. 2, 109-114. https://doi.org/10.1007/BF02826729

Breunig, M., Al-Doori, M., Butwilowski, E., Kuper, P. V., Benner, J., Haefele, K.H. (Eds.), 2015. 3D Geoinformation Science, Lecture Notes in Geoinformation and Cartography. Springer International Publishing, Cham. https://doi.org/10.1007/978-3-319-12181-9

Decontamination, B.W., 2016. Enterprise Geospatial Data Management. U.S. Department of Agriculture,Enterprise Geospatial Management Office, Washington.

Delgado Fernández, T., Fernández, M.D., Andrade, R.E., 2008. The Spatial Data Infrastructure Readiness model and its worldwide application. A Multi-View Framew. to Assess SDIs $117-134$.

Duncan, E.E., Rahman, A.A., 2013. A Multipurpose Cadastral Framework for Developing Countries-concepts. Electron. J. Inf. Syst. Dev. Ctries. 58. https://doi.org/10.1002/j.16814835.2013.tb00411.x

Ellul, C., 2016. Current and Future Status of 3D GIS in the UK 3D GIS. London.

Gang Liu, Qing Zhu, Zhenwen He, Yeting Zhang, Chonglong Wu, Xiaoming Li, Zhengping Weng, 2009. 3d Gis Database Model For Efficient Management of Large Scale Underground Spatial Data, in: 2009 17th International Conference on
Geoinformatics. $\quad$ IEEE, $\quad$ pp.
https://doi.org/10.1109/GEOINFORMATICS.2009.5293455

Gemeda, D.O., 2012. Assessing the Development of Ethiopian National Spatial Data Infrastructure Assessing the Development of Ethiopian National Spatial Data Infrastructure. Wageningen University and Research Centre, The Netherlands.

Ho, S., Rajabifard, A., Kalantari, M., 2015. Invisible Constraints on 3D Innovation in Land Administration: A case Study on the City of Melbourne. L. Use Policy 42 pp.412-425.

Kalantari Oskouei, A., Modiri, M., Alesheikh, A., Hosnavi, R., Nekooie, M.A., 2018. An Analysis of the National Spatial Data Infrastructure of Iran. Surv. Rev. 0, 1-13. https://doi.org/10.1080/00396265.2017.1420586

Kensek, K.M., 2014. Building Information Modeling. Build. Inf. Model. 1-285. https://doi.org/10.4324/9781315797076

Kitsakis, D., Paasch, J., Paulsson, J., Navratil, G., Vucic, N., Karabin, M., Carneiro, A., El-Mekawy, M., 2016. 3D Real Property Legal Concepts and Cadastre: A Comparative Study of Selected Countries to Propose a Way Forward (Overview Report), in: 5th International Workshop on 3D Cadastres. pp. 124.

Kolbe, T.H., Gröger, G., 2003. Towards Unified 3d City Models. Challenges Geospatial Anal. Integr. Vis. II Proc Jt. ISPRS Work. 1-8.

Li, D., Shan, J., Shao, Z., Zhou, X., Yao, Y., 2013. Geomatics for Smart Cities - Concept, Key Techniques, and Applications. Geo-spatial Inf. Sci. 16, 13-24. https://doi.org/10.1080/10095020.2013.772803

Liu, G., Zhu, Q., He, Z., Zhang, Y., Wu, C., Li, X., Weng, Z., 2009. 3D GIS Database Model for Efficient Management of Large Scale Underground Spatial Data. 2009 17th Int. Conf. Geoinformatics, Geoinformatics $2009 \quad 1-5$. https://doi.org/10.1109/GEOINFORMATICS.2009.5293455

Makanga, P., Smit, J., 2010. A Review of the Status of Spatial Data Infrastructure Implementation in Africa. South African Comput. J. 45. https://doi.org/10.18489/sacj.v45i0.36

Mao, W.-Q., 2014. Study on the Construction and Application of 3D Geographic Information Services for the Smart City. ISPRS Ann. Photogramm. Remote Sens. Spat. Inf. Sci. II-4, 41-44. https://doi.org/10.5194/isprsannals-II-4-41-2014

NCSI, 2017a. Oman National Spatial Data Infrastructure Strategy V5.0. National Center for Statistics and Information, Oman.

NCSI, 2017b. Oman National Spatial Data Infrastructure, 1st ed. National Center for Statistics and Information, Oman.

Preka, D., Doulamis, A., 2016. 3d Building Modeling in Lod2 Using the Citygml Standard. ISPRS - Int. Arch. Photogramm. Remote Sens. Spat. Inf. Sci. XLII-2/W2, 11-16. https://doi.org/10.5194/isprs-archives-XLII-2-W2-11-2016

Rajabifard, A., Coleman, D., 2012. Spatially Enabling Government, Industry and Citizens: Research and Development Perspectives. GSDI Association Press.

Rienzo, F. De, Oreste, P., Pelizza, S., 2008. Subsurface Geological-Geotechnical Modelling to Sustain Underground Civil Planning 96, 187-204. https://doi.org/10.1016/j.enggeo.2007.11.002 
Roić, M., 2012. Upravljanje Zemljišnim Informacijama. Katastar, University of Zagreb, Faculty of Geodesy, Zagreb, Croatia.

Salim, M.J., 2017. 3D Spatial Information Intended for SDI : A Literature Review, Problem and Evaluation. J. Geogr. Inf. Syst. 535-545. https://doi.org/10.4236/jgis.2017.95033

Soon, K.H., Tan, D., Khoo, V., Soon, K.H., Tan, D., Khoo, V., 2016. Initial Design to Develop a Cadastral System that Supports Digital Cadastre, 3D and Provenance for Singapore, in: 5th International Workshop on 3D Cadastres. pp. 419-432.

Stoter, J., Ploeger, H., Roes, R., Riet, E. Van Der, Biljecki, F., 2016. First 3D Cadastral Registration of Multi-level Ownerships Rights in the Netherlands, in: 5th International Workshop on 3D Cadastres. pp. 491-504.

Stoter, J., Roensdorf, C., Home, R., Capstick, D., Streilein, A., Kellenberger, T., Bayers, E., Kane, P., Dorsch, J., Woźniak, P., Lysell, G., Lithen, T., Bucher, B., Paparoditis, N., Ilves, R., 2015. 3D Modelling with National Coverage: Bridging the Gap Between Research and Practice, in: Breunig, M., Al-Doori, M., Butwilowski, E., Kuper, P. V, Benner, J., Haefele, K.H. (Eds.), 3D Geoinformation Science: The Selected Papers of the 3D GeoInfo 2014. Springer International Publishing, Cham, pp. 207-225. https://doi.org/10.1007/978-3-319-12181-9_13

Stouffs, R., Tauscher, H., Biljecki, F., 2018. Achieving Complete and Near-Lossless Conversion from IFC to CityGML. ISPRS Int. J. Geo-Information 7, 355. https://doi.org/10.3390/ijgi7090355

van den Brink, L., Stoter, J., Zlatanova, S., 2013. Establishing a National Standard for 3D Topographic Data Compliant to CityGML. Int. J. Geogr. Inf. Sci. 27, 92-113. https://doi.org/10.1080/13658816.2012.667105

Wang, Z., Qu, H., Wu, Z., Wang, X., 2018. Geo3DML: A standard-Based Exchange Format for 3D Geological Models. Comput. Geosci. 110, 54-64. https://doi.org/10.1016/j.cageo.2017.09.008

Yan, J., Zurich, E.T.H., Jingya, S.C., 2018. Three-dimensional Data Modelling For Underground Utility XLII, 1-5.

Yao, Z., Nagel, C., Kunde, F., Hudra, G., Willkomm, P., Donaubauer, A., Adolphi, T., Kolbe, T.H., 2018. 3dcitydb - a 3d Geodatabase Solution for the Management, Analysis, and Visualization of Semantic 3d City Models Based on Citygml. Open Geospatial Data, Softw. Stand. 3. https://doi.org/10.1186/s40965-018-0046-7

Zhao, Y., Alothman, A., Kawiani, M., 2007. an Efficient 3D GIS Data Extraction Method With Digital Photogrammetry Technology in Arid Area. ASPRS 2007 Annu. Conf. Florida 17. 